\title{
Easy detecting signal of cognitive decline in healthy community-dwelling elderly people
}

\author{
Takeshi Hatta $^{1^{*}}$, Taketoshi Hatta ${ }^{2}$, Chie Hotta $^{1}$, Emi Ito $^{3}$, Akihiko Iwahara $^{4}$, Naoko Nagahara ${ }^{1}$, \\ Junko Hatta ${ }^{5}$, Kazumi Fujiwara ${ }^{1}$, Nobuyuki Hamajima ${ }^{3}$ \\ ${ }^{1}$ Kansai University of Welfare Sciences, Osaka, Japan; ${ }^{*}$ Corresponding Author: thattajp@yahoo.co.jp \\ ${ }^{2}$ Gifu University of Medical Sciences, Gifu, Japan \\ ${ }^{3}$ Nagoya University, Nagoya, Japan \\ ${ }^{4}$ Wakayama Prefectural Medical University, Wakayama, Japan \\ ${ }^{5}$ Aichigakuin University, Nagoya, Japan
}

Received 4 October 2013; revised 9 November 2013; accepted 21 November 2013

Copyright (C) 2013 Takeshi Hatta et al. This is an open access article distributed under the Creative Commons Attribution License, which permits unrestricted use, distribution, and reproduction in any medium, provided the original work is properly cited.

\begin{abstract}
The relationship between changes of elderly people's participation in social activities and their cognitive functions was examined. Healthy, middle and upper-middle aged people $(n=407)$ responded to the Nagoya University Cognitive Assessment Battery and to a questionnaire inquiring about their participation in social activities. The results suggested that those whose participation in social activities increased in the last 6 months showed better verbal functioning than those whose participation was unchanged or decreased. Moreover, those whose social participation decreased showed inferior memory function compared to those whose social participation was unchanged, or increased. Furthermore, those whose social participation increased had better information processing speed than those whose social participation decreased. These results suggest that changes in social activities might act as an important signal that is indicative of the cognitive decline in elderly people, which would be useful to local health care managers in the elderly people's community.
\end{abstract}

Keywords: Signal of Cognitive Decline; Cognitive Aging; Social Activity; Memory; Information Processing Speed; Verbal Function

\section{INTRODUCTION}

Reviews on cognitive aging have stressed the importance of accumulating more data for understanding de- velopmental changes after middle age. Studies have also strongly advocated the need to accumulate information in order to cultivate lifestyles to prevent early stage cognitive decline [1-4].

A number of studies have investigated lifestyles and cognitive functions in elderly. These studies have generally reported that people engaging in so-called cognitive social activities, such as reading books and journals and visiting to libraries and museum, have better cognitive functions than people who do not habitually engage in such activities [5-14]. However, we do not know whether the above finding is universal, and depends on factors such as research methods that were used and population characteristics of the participants, among others. Therefore, further investigations are needed to establish if the relationship between reduced cognitive social activities and declining cognitive function is culture free, pragmatically valid, and easy to detect signals of cognitive in communities of elderly people. This is especially important because the prevention of cognitive decline in elderly people is a critical task for health managers of local government.

This study was undertaken as a part of the neuropsychological section of the Yakumo study, which is a largescale Japanese cohort study that began in 1981, designed to investigate the health of people living in the town of Yakumo in the island of Hokkaido in Japan [15]. The department of preventive medicine of the Nagoya University Medical School and the town of Yakumo jointly conducted the study. Investigations were conducted in the fields of epidemiology, internal medicine, orthopedics, neuropsychology, ophthalmologic, otolaryngology, and urology. Participants in the study were engaged in a variety of jobs, not only while color, but also agriculture, fishery and forestry. They had a relatively homogeneous 
socio-economic status typical of a normal sample of Japanese people living in Yakumo town.

We aimed to develop a quick and easy assessment technique to alert health management personnel in local government at the beginning of cognitive decline in elderly people. Previous studies have used questionnaires to identify cognitive decline in elderly people. However, questionnaire items in nearly all previous studies have addressed participants' current, statistic state of social activities, and had not inquired about the changing state of their social activities. Therefore, we developed a new questionnaire consisting of the items followed by Buchman, Boyle, Wilson, Feilschman, Leugans, and Bennett [16], with the addition of a new item inquiring about the changes in the social activities of participants. In preparing the questionnaire, we took into consideration the fact that the participants in the current study were from a rural town that did not have enough infrastructures for social activities available to participants in previous studies, as well as the socioeconomic status of our participants, the majority of whom were retired and/or working in the primary sector of industry.

The questionnaire was administered to middle-and upper-middle-aged, healthy people living in the community. Once again, the purpose of this study was to examine if the relationship between cognitive social activities and cognitive functions reported in the study by Buchman, et al, was used universally and had cross cultural validity, as well as to identify practical and valid indications of cognitive decline. If the questionnaire were sensitive enough to detect a cognitive decline in a community of elderly people in Japan, it would be a quick and convenient tool useful for health management staffs of local government.

\section{METHODS}

\subsection{Study Sample}

The data were collected in 2011. Middle aged and older adults $(\mathrm{N}=407,162$ men and 245 women, age ranged 40 to 89 years, mean age 66.1 years, $\mathrm{SD}=10.1$ ) participated in the study.

Participants were consisted of 40's (23 men and 46 women), 50's (17 men and 45 women), 60's (52 men and 76 women), 70's (39 men and 56 women) and 80's (24 men and 29 women).

Participants that voluntarily completed both questionnaires described below, without missing any questions and all completed a medical examination without the diagnosis of serious conditions leading to frailty, such as metastasized neoplastic disease, psychiatric illness or sign of dementia were included in the study. Data from 13 participants were excluded due to incomplete response to the Daily Lifestyle Questionnaire.

\subsection{Measures}

Social activity: The questionnaire on Daily Lifestyle inquired about various aspects of the social activities of the participants, including the frequency of leisure activity, interactions, visits to senior citizen's meetingamong others. This questionnaire was followed bythe questionnaire by Bennett, Scheider, Buchman, Mendes de Leon, Binais, and Wilson [17] and Buchman, et al. [16]. The six items in Buchman's original questionnaire included the following items: 1) Go to restaurant/sporting event/ game; 2) Go on day trips or overnight trips; 3) Do unpaid community/volunteer work; 4) Visit relatives/friends houses; 5) Participate in groups such as the center for senior citizens; 6) Attend religious services. Participants responded by selecting one of the following three alternatives: less than several times per week, several times per months, or several times per six months. We added a new item to this questionnaire that address change in social activities; "In the last 6 months, did you have the opportunity to go out more than before?" In response to this question, the participants selected one of the three following alternatives, "increased, decreased, or unchanged." Probably due to the relatively high homogeneity of participants' background, a large response bias in choice distribution was shown for the most items in the questionnaire (i.e., participants' responses were nearly unique and were not distributed into several groups). This was not the case for the responses to the new item. Therefore, responses to the new item were analyzed in this study, because this item represented a different perspective for measuring the social activities on elderly people.

Cognitive function: Participants also responded to the Nagoya University Cognitive assessment Battery (NU$\mathrm{CAB}$ ) that assessed individual cognitive functions, such as attention, language, memory, working memory and executive functions [18]. Both reliability and validity of the UN-CAB have been reported elsewhere [19-23]. The NU-CAB consisted of test items such as MMSE [24], Logical Memory Test (Japanese short version of Wechsler Memory Scale), Money Road Test (for visuo-spatial function assessment), Stroop Test, D-CAT (digit cancellation test) and Verbal Fluency Test (letter fluency test; LFT and semantic fluency test: SFT). The validity examination by means of the NIRS (Near- infrared Spectroscopy) identified robust activation of prefrontal cortex in the D-CAT and LFT, and both frontal and temporal cortices activation in the SFT and the Logical Memory Test [25]. In this study, we used 13 measures (MMSE, Logical memory, Money road test, Stroop dot color naming speed, Stroop dot color naming errors, Stroop letter color naming speed, Stroop letter color naming errors, D-CAT 1 letter cancellation performance, D-CAT I letter missing performance, D-CAT 3 letters cancella- 
tion performance, D-CAT 3 letters missing performance, LFT, and SFT.

\section{RESULTS}

As expected, the distribution of responses to six items in the questionnaire was similar to the previous studies by Bennett, et al. [17] and Buchman, et al. [16] and displayed a strong bias. For example, in the item; "go to restaurant/sporting event/game," the responses using the three alternative, less than several time per week, several times per month, and several times per six month were 7 , 111 , and 276, respectively, for the item "go to day trips or overnight trips" were 16, 62 and 316, respectively, for the item "do unpaid community/volunteer work" were 268,159 , and 17, respectively. The only exception of response bias was for the item, "In last 6 months, did you have the opportunity to go out more than before." Therefore, we used responses to this item to classify participants into three groups, "increased", "unchanged" and "decreased". The population sizes of the three groups were 43, 260, and 91, respectively (mean age were $63.1(\mathrm{SD}=1.5), 65.9(\mathrm{SD}=0.6)$, and $68.081 \mathrm{SD}=$ 1.1), respectively. An analysis of variance (ANOVA) was conducted and the results showed that statistically significant difference of the group was found in "the opportunity to go out more than before, "between "increased" and "decreased" group between "increased" and "decreased" (F 1, 391 = 3.39, $p=0.03$ ) whereas no statistical difference was identified other pairings.

We also examined the relation between social activity and cognitive function for this item, which was "In last 6 months, did you have the opportunity to go out more than before." The performance scores for different cognitive measure did not have an identical range and therefore we transformed the performance scores into $\mathrm{Z}$ score for statistical analyses.

Table 1 shows mean performance and standard deviation for 13 measures of cognitive performance.

Table 2 shows the results of ANOVA, which indicated that MMSE, D-CAT 1-digit performance, D-CAT 3-digits performance, Logical Memory Test, LFT, and SFT had significant group differences. Money road test and Stroop dot color naming speed showed marginally significant differences. These findings suggest that memory related measures and information processing speed related measures showed group difference, whereas error related measures showed no group difference. Significant differences were subjected to post-hoc analyses [Bonferroni $\alpha(0.05)$ ] that revealed LFT and SFT was a significant different between the increased and unchanged groups), Logical Memory test, MMSE and Money were a significant different between unchanged and decreased groups, and D-CAT digit 1, D-CAT digit 3, LFT and SFT showed a significant different between
Table 1. Mean performance ( $Z$ score transformed) and standard deviation (in the parentheses) for 15 measures.

\begin{tabular}{|c|c|c|c|}
\hline Measures & $\begin{array}{c}\text { Group 1 } \\
\text { (increased) }\end{array}$ & $\begin{array}{c}\text { Group } 2 \\
\text { (no change) }\end{array}$ & $\begin{array}{c}\text { Group } 3 \\
\text { (decreased) }\end{array}$ \\
\hline $\begin{array}{c}\text { D-CAT } \\
\text { (1 digit total performance) }\end{array}$ & $\begin{array}{c}0.226 \\
(1.089)\end{array}$ & $\begin{array}{c}0.037 \\
(0.948)\end{array}$ & $\begin{array}{l}-0.212 \\
(1.058)\end{array}$ \\
\hline $\begin{array}{c}\text { D-CAT } \\
\text { (1 digit miss performance) }\end{array}$ & $\begin{array}{c}0.122 \\
(1.483)\end{array}$ & $\begin{array}{l}-0.024 \\
(0.925)\end{array}$ & $\begin{array}{c}0.039 \\
(0.983)\end{array}$ \\
\hline $\begin{array}{c}\text { D-CAT } \\
\text { (3 digits total performance) }\end{array}$ & $\begin{array}{c}0.314 \\
(1.155)\end{array}$ & $\begin{array}{l}0.0165 \\
(0.958)\end{array}$ & $\begin{array}{l}-0.209 \\
(0.998)\end{array}$ \\
\hline $\begin{array}{c}\text { D-CAT } \\
\text { (3 digits miss performance) }\end{array}$ & $\begin{array}{c}0.044 \\
(1.299)\end{array}$ & $\begin{array}{l}-0.057 \\
(0.883)\end{array}$ & $\begin{array}{c}0.088 \\
(1.076)\end{array}$ \\
\hline Logical Memory Test & $\begin{array}{l}-0.024 \\
(1.064)\end{array}$ & $\begin{array}{l}0.100 \\
(0.936)\end{array}$ & $\begin{array}{l}-0.242 \\
(1.116)\end{array}$ \\
\hline Letter Fluency Test & $\begin{array}{c}0.578 \\
(1.042)\end{array}$ & $\begin{array}{l}-0.026 \\
(0.957)\end{array}$ & $\begin{array}{l}-0.182 \\
(1.058)\end{array}$ \\
\hline Semantic Fluency Test & $\begin{array}{c}0.253 \\
(1.232)\end{array}$ & $\begin{array}{c}0.111 \\
(0.928)\end{array}$ & $\begin{array}{l}-0.396 \\
(0.934)\end{array}$ \\
\hline MMSE & $\begin{array}{l}-0.126 \\
(1.041)\end{array}$ & $\begin{array}{c}0.112 \\
(0.929)\end{array}$ & $\begin{array}{l}-0.183 \\
(1.110)\end{array}$ \\
\hline Money Road Test & $\begin{array}{l}-0.022 \\
(1.053)\end{array}$ & $\begin{array}{l}0.0829 \\
(0.969)\end{array}$ & $\begin{array}{l}-0.205 \\
(1.055)\end{array}$ \\
\hline $\begin{array}{l}\text { Stroop dot color } \\
\text { naming }(\mathrm{sec})\end{array}$ & $\begin{array}{l}-0.122 \\
(1.123)\end{array}$ & $\begin{array}{l}-0.039 \\
(0.887)\end{array}$ & $\begin{array}{c}0.208 \\
(1.240)\end{array}$ \\
\hline $\begin{array}{l}\text { Stroop dot color } \\
\text { naming error (sec) }\end{array}$ & $\begin{array}{l}-0.076 \\
(0.750)\end{array}$ & $\begin{array}{l}-0.015 \\
(1.000)\end{array}$ & $\begin{array}{c}0.015 \\
(0.894)\end{array}$ \\
\hline $\begin{array}{l}\text { Stroop letter color } \\
\text { naming (sec) }\end{array}$ & $\begin{array}{l}-0.148 \\
(0.882)\end{array}$ & $\begin{array}{c}0.009 \\
(1.020)\end{array}$ & $\begin{array}{c}0.079 \\
(1.023)\end{array}$ \\
\hline $\begin{array}{l}\text { Stroop letter color } \\
\text { naming error }(\mathrm{sec})\end{array}$ & $\begin{array}{l}-0.030 \\
(0.659)\end{array}$ & $\begin{array}{c}0.021 \\
(1.116)\end{array}$ & $\begin{array}{l}-0.044 \\
(0.738)\end{array}$ \\
\hline
\end{tabular}

Table 2. Results of the analysis of variance (ANOVA) scores and probability of significant confidence.

\begin{tabular}{ccc}
\hline Measures & F score & Probability \\
\hline D-CAT (1 digit total performance) & 3.388 & 0.035 \\
D-CAT (1 digit miss performance) & 0.453 & 0.636 \\
D-CAT (3 digits total performance) & 4.234 & 0.015 \\
D-CAT (3 digits miss performance) & 0.818 & 0.442 \\
Logical Memory Test & 4.016 & 0.019 \\
Letter Fluency Test & 3.637 & 0.028 \\
Semantic Fluency Test & 5.965 & 0.003 \\
MMSE & 3.553 & 0.030 \\
Money Road Test & 2.819 & 0.061 \\
Stroop dot color naming (sec) & 2.452 & 0.087 \\
Stroop dot color naming error (sec) & 0.134 & 0.874 \\
Stroop letter color naming (sec) & 0.744 & 0.476 \\
Stroop letter color naming error $(\mathrm{sec})$ & 0.162 & 0.850 \\
\hline
\end{tabular}

increased and decreased groups.

\section{DISCUSSION}

Understanding the relationship between cognitive social activities and cognitive functions in the elderly is an important topic in contemporary aging studies. Moreover, 
extending and preserving the healthy social life of elderly people is a pressing issue in the developed countries with aged societies, because of the increasing social cost of caring for elderly people that is a substantial burden on the national and local government economies of these countries. The present study was designed to gain further insights into this pressing issue. Needless to say, cognitive social activities depend on the culture, and are regulated by geographical living area, as well as era. Therefore, it is essential to establish the findings of previous studies on the relationship between cognitive social activities and cognitive functions in the elderly and have cross-cultural validity, in samples of elderly people from different cultural backgrounds. In this study, we used the same questionnaire that was used previously by Buchman, et al. [16] with one modification.

The results of the current study indicated a large response bias in most items that was observed in the previous study [16]. Therefore, our results suggest that the questionnaire used in the studies by Buchman, et al. is not necessarily culture free, or has enough cultural sensitivity to detect relationship between cognitive social activities and cognitive functions, cross culturally. The current study was also designed to identify early cues of cognitive decline in elderly people for the benefit of health managing staffs. In order to do this, a new questionnaire item that inquired about changes in cognitive social activities was included in this study that inquired about changes in social activities. On the basis of this question, the participants were divided into three groups: those whose cognitive social activities "increased, decreased, or remained unchanged."

An ANOVA indicated that in performing LFT and SFT, the increased group showed better performances than the unchanged group. This may have been caused by the increased opportunity for verbal communication in increased group, and may reflect better function of frontal and temporal regions in this group. Moreover, in the Logical Memory test, and MMSE, the unchanged group showed superior performance than that of decreased group. This may reflect poor memory function in the decreased group, as well as reduced function of the temporal region function in this group. Furthermore, the increased group showed better performance in D-CAT digit 1, D-CAT digit 3, LFT and SFT than the decreased group, probably indicative of better attention reflecting superior function of the frontal and temporal regions.

Firstly, these findings suggest that error-related measures have little value in the assessment of healthy, elderly people. Secondly, our results suggest that the questionnaire items used in previous, large-scale studies that investigated the relationship between social activity and cognitive function are not necessarily universally valid. When population sample is highly homogenous, inquir- ing about social activities by measuring cognitive (e.g., reading book, journal, newspaper, writing letter, diary), hobby activities (e.g., gardening, drawing), leisure (e.g., day trip, overnight trip), and interactive activities (e.g., religious meeting, senior center) may not be sufficiently sensitive. Thirdly, the present findings suggest that general psychological ability measured by a question about changes in cognitive social activities is useful for detecting the cognitive decline healthy elderly people, because it may be strongly related to the basic psychological intention to engage in social activities.

This psychological intention could be expressed in words such as engagement, involvement, purposiveness or imitativeness and implies a forward-looking, but not necessarily goal-achieving motivation, which may form the general basis of all social and cognitive activities. Therefore, it is important to notice early sign of "imitativeness ability" with community members. Early detection could help local government health promotion staff to reduce the social and health care costs that are an increasing burden on the national budget. One of the simplest cues of changing of "imitativeness ability" in elderly people is whether their opportunities for go-out are decreasing or still unchanged.

\section{ETHICS}

Ethical approval was obtained from the Ethical Committee of Nagoya University Medical School for Yakumo Study (Genetic polymorphism study for health checkup examinees in Yakumo town, 2011 \# 643) and written informed consent for participation and data publication were obtained from each participant.

\section{REFERENCES}

[1] Cabeza, R., Nyberg, L. and Park, D. (2005) Cognitive neurosciences of aging. Oxford University Press, Oxford.

[2] Iwahara, A. and Hatta, T. (2009) Life style and cognitive reserve. Japanese Journal of Psychological Review, 52 416-426.

[3] Salthouse, T. A. (2010) Selective review of cognitive aging. Journal of the International Neuropsychological Society, 17, 1-7.

[4] Stern, Y. (2009) Cognitive reserve. Neuropsychologia, 47, 2015-2028. http://dx.doi.org/10.1016/j.neuropsychologia.2009.03.004

[5] Fabrigoule, C., Letenneur, L., Dartigues, J. F. and Zarroul, M. (1995) Social and leisure activities and risk of dementia: A prospective longitudinal study. Journal of American Geriatrics Society, 43, 485-490.

[6] Fratiglioni, L., Paillard-Borg, S. and Winblad, B. (2004) An active and socially integrated lifestyle in late life may protect against dementia. The Lancet Neurology, 3, 343353. http://dx.doi.org/10.1016/S1474-4422(04)00767-7 
[7] Hultsch, D. F., Hertzog, C., Small, B. J. and Dixon, R. A. (1999) Use it or lose it: Engaged lifestyle as a buffer of cognitive decline in aging? Psychology and Aging, 14, 245-263. http://dx.doi.org/10.1037/0882-7974.14.2.245

[8] Rabbitt, P.M.A., Lowe, C. and Shilling, V. (2001) Frontal tests and models of cognitive aging. European Journal of Psychology, 13, -28.

[9] Scarmeas, N. and Stern, Y. (2003) Cognitive reserve and lifestyle. Journal of Clinical and Experimental Neuropsychology, 25, 625-633.

http://dx.doi.org/10.1076/jcen.25.5.625.14576

[10] Scarmeas, N., Levy, G., Tang, M-X., Manly, J. and Stern, Y. (2001) Influence of leisure activity on the incidence of Alzheimer's disease. Neurology, 57, 2236-2242. http://dx.doi.org/10.1212/WNL.57.12.2236

[11] Schooler, C. and Mulatu, M. S. (2001) The reciprocal effects of leisure time activities and intellectual functioning in older people. A longitudinal analysis. Psychology and Aging, 16, 466-482.

http://dx.doi.org/10.1037/0882-7974.16.3.466

[12] Wilson, R. S., Barnes, L. L. and Bennett, D. A. (2003) Assessment of lifetime participation in cognitively stimulating activities. Journal of Clinical and Experimental Neuropsychology, 25, 634-642.

http://dx.doi.org/10.1076/jcen.25.5.634.14572

[13] Wilson, R. S., Barnes, L. L. and Bennett, D. A. (2007) Assessment of lifetime participation in cognitively stimulating activities. In: Stern, Y., Ed., Cognitive Reserve: Theory and Applications, Taylor \& Francis, New York, 159-172.

[14] Wilson, R. S., Barnes, L. L., Krueger, K. R., Hoganson, G., Bienias, J. L. and Bennett, D. A. (2005) Early and late life cognitive activity and cognitive systems in old age. Journal of the International Neuropsychological Society, 11, 400-407.

[15] Hatta, T. (2007) Report of the neuropsychological examination in middle and upper-middle people of Yakumo Cohort. Nagoya University, Nagoya, 1-679.

[16] Buchman, A. S., Boyle, P. A., Wilson, R. S., Feilschman,
D. A., Leugans, S. and Bennett, D. A. (2009) Association between late life social activity and motor decline in order adults. Archives of Internal Medicine, 169, 1139-1146. http://dx.doi.org/10.1001/archinternmed.2009.135

[17] Bennett, D. A., Schneider, J. A., Buchman, A. S., Mendes de Leon, C., Binais, J. L. and Wilson, R. S. (2005) The rush memory and aging project: Study design and baseline characteristics of the study cohort. Neuroepidemiology, 25 163-175. http://dx.doi.org/10.1159/000087446

[18] Hatta, T. (2003) Brain and Behavior. Ishiyaku-syuppan, Tokyo.

[19] Hatta, T. (2004) Development of a test battery for assessment of cognitive function in community health examination. Journal of Human Environmental Studies, 2, 15-20. http://dx.doi.org/10.4189/shes.2.2_15

[20] Hatta, T., Nagahara, N., Iwahara, A. and Ito, E. (2005) Three word recall and logical memory in normal aging. Journal of Human Environmental Studies, 3, 7-12.

[21] Ito, E. and Hatta, T. (2006) .Reliability and validity of Japanese verbal fluency test. Japanese Journal of Neuropsaychology, 22, 146-152.

[22] Hatta, T., Ito, Y. and Yoshizaki, K. (2006) Digit cancelation test (manual 2nd edition) FIS, Osaka.

[23] Hatta, T., Kanari, A., Mase, M., Kabasawa, M., Ogawa, T., Shirataki, T., Hibino, S., Iida, A., Nagano, Y., Abe, J. and Yamada, K. (2008) Brain mechanism in Japanese verbal fluency test: Evidence from examination by NIRS (NearInfrared Spectroscopy). Asia Pacific Journal of Speech Language \& Hearing, 11, 103-110.

[24] Folstein, M. F., Folstein, S.E. and McHugh, P. R. (1975) "Mini-mental state": A practical method for grading the cognitive state of patients for the clinician. Journal of Psychiatric Research, 12, 189-198. http://dx.doi.org/10.1016/0022-3956(75)90026-6

[25] Hatta, T., Kanari, A., Mase, M., Nagano, Y., Shirataki, T. and Hibino, S. (2009) Strategy effects on word searching in Japanese letter fluency tests: Evidence from the NIRS findings. Reading \&Writing, 22, 1041-1052. http://dx.doi.org/10.1007/s11145-008-9143-9

\section{NOTES OF THE ABBREVIATIONS}

ANOVA: Analysis of Variance

D-CAT: Digit Cancellation Test

LFT: Letter Fluency Test

MMSE: Mini Mental State Examination

NIRS: Near-Infrared Spectroscopy

NU-CAB: Nagoya University Cognitive Assessment Bat-

tery

SFT: Semantic Fluency Test 